\title{
Humility and respect: core values in medical education
}

Larry D Gruppen

CONTEXT Many of the values and behaviours described in the original Hippocratic Oath are relevant to medical education. In particular, the values of intellectual humility and respect for one's colleagues are essential in all scientific disciplines. There are three contexts within medical education from which to consider humility and respect: uncertainty; theory, and colleagues.

UNCERTAINTY As medical education grows in scope and participation, we will be required to acknowledge that we 'know not' with increasing frequency. The uncertainty of what we do and do not know is compounded by uncertainty about whether ignorance is individual or corporate. As difficult as it is to admit that we 'know not', it is dangerous NOT to recognise the limits of our knowledge and experience.

THEORY Theories are critical tools in understanding complex phenomena. They identify constructs and relationships that are important and those that are irrelevant. We tend to forget that theories are models or simplified representations of reality and not in themselves 'truths'. Viewing problems from other theoretical perspectives can widen our horizons by allowing us to identify possibly important concepts and relationships that we have not considered.

COLLEAGUES Colleagues are invaluable for helping us respond to our 'knowing not' and for providing alternative perspectives when our theories lead us astray. However, colleagues come in many guises and include close colleagues, as well as those in distant fields.

\section{OBSTACLES TO HUMILITY AND}

RESPECT As obviously desirable as humility and respect seem to be, there are conflicts that prevent us from being humble and respectful. Such conflicts include other salient professional values, such as critical scepticism, competition and confidence.

HONOURING THE OATH Adoption of the values of humility and respect in medical education can be fostered through intentional behaviours, both as individuals and as a discipline. We can deliberately seek to broaden our horizons to promote intellectual humility. We can foster collaboration among colleagues who come from different places, both geographically and intellectually. Finally, we can pursue 'academic cultural exchanges' with other fields and disciplines to learn and share in different ways of thinking.

Medical Education 2014: 48: 53-58

doi: $10.1111 /$ medu. 12269

Discuss ideas arising from the article at

'www.mededuc.com discuss'

Department of Medical Education, University of Michigan

Correspondence: Larry D Gruppen, Department of Medical

Medical School, Ann Arbor, MI, USA

Education, University of Michigan Medical School, G1111

Towsley Center, 1500 East Medical Center Drive, Ann Arbor, MI

48109-5201, USA. Tel: 001734936 1644;

E-mail: lgruppen@umich.edu 
Editor's note: This article has been written in response to the following line from Lasagna's modernisation of the Hippocratic Oath ${ }^{1}$

'I will not be ashamed to say "I know not", nor will I fail to call in my colleague when the skills of another are needed for a patient's recovery.'

\section{INTRODUCTION}

The original Hippocratic Oath (and its subsequent revisions) is a statement of commitment on the part of a doctor entering the professional community. The Oath espouses the values of the profession and the behaviours of the practitioner that stem from these values. This particular sentence of the Oath ${ }^{1}$ highlights the values of intellectual humility and respect for the skills and knowledge of others. It embeds these values in the commitment to care for the patient, the core purpose of practice in this profession.

What might this sentence of the Oath have to say to us in the medical education community? Medicine is an ancient profession, whereas medical education is a much younger discipline. Medicine has been held up often as a model profession, whereas medical education is often unknown as a profession. Doctors follow a systematic and defined educational pathway to enter their profession, whereas medical educators often follow idiosyncratic routes. Nonetheless, both disciplines are predicated on the ethical application of scientific knowledge to important problems within a professional community. This paper will explore how this part of the Hippocratic Oath $^{1}$ relates to medical education scholarship and practice by examining the problem of 'knowing' and 'knowing not', the nature of theory, and the diversity of our colleagues. It will also consider obstacles that may prevent us from expressing these values and ways by which these values might be promoted.

\section{UNCERTAINTY: 'KNOWING' AND 'KNOWING NOT'}

There are many circumstances in which a medical educator might say: 'I know not.' The discipline of medical education has grown enormously over recent decades, as is evidenced by the expanding numbers of journals and textbooks devoted to health professions education, the number and attendance figures of medical education conferences, and the proliferation of professional societies and organisations. Beyond the multiplication of medical education outlets, there has also been a growing division of the community into specialty groups focused on such areas as standardised patients, simulation, communication, professionalism and clinical reasoning, to say nothing of the various professions subsumed under the umbrella of health care education. Although this multiplication and division combine to represent a healthy sign of the development of the discipline, they carry the inevitable consequence of making it impossible for any individual to be aware of, much less master, all the domains contained within health professions education. Because there is so much more to know, there is so much more to 'know not'.

As the Oath emphasises in the declaration 'I will not be ashamed...', knowing and knowing not are not purely intellectual states. They are attended by powerful emotions. Indeed, the emotional aspects of cognitive judgements and states are central to the professional behaviour and values of medical educators. ${ }^{2}$ These influence the individual's motivation, values and priorities, as well as such attitudes as pride and humility.

The experience of 'knowing not' is particularly challenging for new members of the community and for those delving into new areas. Does 'knowing not' arise from individual ignorance or is it a reflection of the fact that the community itself does not know? Individual ignorance can be addressed through learning from the community. However, collective ignorance must be addressed through research and the dissemination of new understanding to the community.

Although this sentence of the Oath focuses on our experience of and response to the discovery 'I know not', there is reason to be leery of the sanguine feeling of 'knowing'. The literature on self-assessment has repeatedly observed that people generally overestimate their knowledge and are overconfident in their judgements. ${ }^{3}$ The fact that confidence can increase with expertise ${ }^{4}$ raises even greater concerns. Indeed, confidence can be a sign of danger because it is not strongly correlated with truth or correctness. The fact that we are often mistaken in our judgements of what we know, as well as in those of what we know not, lends urgency to the call for intellectual humility and the attendant behaviour of 
calling in colleagues, perhaps even when we believe we do know.

\section{THEORY IN MEDICAL EDUCATION}

Like individual mental models and naïe theories, formal theories are wonderful tools for making sense of complex phenomena. However, like any model, a theory aids understanding by simplifying reality, in part, by ignoring certain features or relationships. One's mental model of an automobile does not include a specific colour or the kind of pavement on which it rests, but leaves out those aspects as irrelevant. Similarly, every theory defines things that are and are not worth considering. The filtering effects of theory are necessary for dealing with a complex world and are, indeed, an essential component of human perception itself. ${ }^{5}$ Theory enables the restructuring and reorganisation of one's comprehension of a situation. ${ }^{6}$ This is both a boon in terms of facilitating ease of understanding, and a bane if whatever is ignored turns out to be important.

The simplifying benefits of theory are particularly important in problems in medical education. Such problems are extremely complex because they incorporate many entities and many interactions. ${ }^{7} \mathrm{We}$ need to consider the individual learner, the teacher, the content, and the context in most educational problems and the only way to do so is to simplify. Our theories (whether implicit or explicit) guide our simplifications. However, recognising that what we ignore may be as important as what we focus on will help us to appreciate other theoretical perspectives that may focus on things we neglect.

As an example, cognitive theories of learning focus on knowledge acquisition, but largely ignore the social context of learning. By contrast, social learning theories highlight the social context, both for its role in learning and for putting learning into practice. However, these theories rarely address the cognitive structure of knowledge representation. It is not that one theory is better or that both are flawed because they simplify reality. Instead, they may be complementary, and a medical educator with a particular theoretical perspective might benefit from looking at a problem from another theoretical perspective.

As beneficial as multiple theoretical perspectives may be, it is easier to maintain a single perspective and argue conclusions and implications from a pur- ist's standpoint than to take a more heterodox position among theoretical camps. Considering other theoretical points of view requires patience, tolerance for ambiguity, and willingness to explore and suspend initial disbelief.

\section{THE DIVERSITY OF COLLEAGUES}

The core professional value of intellectual humility represented in the statement 'I will not be ashamed to say "I know not"' leads directly to the other key value of respect for one's colleagues, which is reflected in the willingness to 'call in my colleagues when the skills of another are needed'.

Medical education is a hybrid field that draws not only from medicine and education, but also from many of the social sciences. ${ }^{8,9}$ As such, its very foundation depends on the maintenance of respect for different points of view and different disciplinary perspectives. Medical education must synthesise elements of each perspective to form something new in the marriage of multiple viewpoints, rather than enforcing separation in the name of theoretical purity. Respect for the perspectives of colleagues and their expertise is essential to the practice and scholarship of medical education.

Who are our medical education colleagues? There are concentric circles of people whom we might consider. In the inner circle are other medical educators, especially those who work in the same areas as ourselves and share similar theoretical perspectives (although these people may also be our fiercest competitors!). The next circle out includes educators more generally, from whom we can learn principles and procedures to apply in medical education. Beyond this circle are other scholars and practitioners in the social sciences, the humanities, business and management, and other sciences. Colleagues from each of these circles can represent valuable assets when one 'knows not'.

The hybrid nature of medical education and the linking of practice with theory places special emphasis on the maintenance of respect between physicians and non-physicians. Individuals within both groups bring unique skills, knowledge and insights to problems in medical education and must respect the particular expertise of their colleagues. It is inappropriate and unwise to criticise one another as 'impractical' or 'anti-intellectual'. Medical education requires a healthy recognition of the practical application of the specialised edu- 
cational knowledge and skills that we all bring to the problems we address.

\section{OBSTACLES TO DEMONSTRATING HUMILITY AND} RESPECT

Although no one would argue against the practice of humility and respect, challenges may arise in situations in which these values conflict with other professional values. One such conflict occurs when respect and critical scepticism meet. As a sciencebased discipline, medical education grows through the dialectic of theoretical argument and empirical evidence. Respect, then, does not involve uncritical acceptance of the viewpoints of others or a politically correct acceptance of the legitimacy of any claim as someone's 'right'. Rather, respect is seasoned with the same critical scepticism that underlies one's own intellectual humility - a fundamental questioning of claims, whether one's own or someone else's. Respect requires a balance between commitment to a theoretical position or practical intervention and a willingness to change in the face of evidence and compelling argument. Lively and open discussion about the strengths and weaknesses of ANY theoretical position is required to advance the field of medical education and the underlying science, but this can test the boundary between respect and scepticism.

Albert et al. ${ }^{10,11}$ have highlighted this tension by juxtaposing medical educators who focus primarily on practical applications with those who focus on fundamental, conceptual questions that may or may not have immediate application. Protagonists from these contrasting perspectives may often find themselves on opposite sides in arguments about the relevance of particular studies, the allocation of scarce resources, and the scientific credibility of medical education as a discipline. In such conflicts, respect can suffer.

Similarly, proponents of quantitative versus qualitative research methodologies have not always given due consideration to the claims and arguments of parties in the other camp. This particular tension may have found a compromise in 'mixed-methods' research, which seeks to combine the strengths of qualitative methods for discovering relationships with the strengths of quantitative methods for quantifying and assessing the generalisability of phenomena. However, there were (and still are) numerous examples of contexts in which willingness 'to call in my colleagues when the skills of another are needed' is strained, if not absent, in relation to the selection of methodological orientation.

A values conflict may arise between humility and confidence. Cognitively, humility comes at the price of confidence and clarity. The task of perpetually entertaining the possibility that one is wrong is demanding. It is an 'unnatural' activity, given that our cognitive processes are adapted to make sense of a complex world very rapidly and to reduce uncertainty as quickly and completely as possible, even at the risk of error. ${ }^{12-14}$ Intellectual humility also carries with it the prospect that one might need to change one's knowledge, beliefs and priorities, which is rarely an easy or comfortable activity. Our natural response to contradiction is to resist, not to accept and consider the potential validity of the contradiction.

Both humility and respect may suffer in the face of competitive funding and publication opportunities. The 'publish or perish' mentality tends towards pride, rather than humility, and the criticism of colleagues rather than respect. Collaboration with colleagues, which depends on the values of humility and respect, is encouraged by many, but may run aground on the rocks of competition and fame.

\section{HONOURING THE OATH}

If we in medical education accept the importance of intellectual humility and collegial respect as highlighted in the Hippocratic Oath, how might we put these values into practice?

\section{Broadening our horizons to promote intellectual humility}

Intellectual parochialism and pride are difficult to maintain when one is required to confront the ideas of others. Similarly, one cannot effectively call in colleagues if one is ignorant of their skills. Thus, one practical response would be to expose oneself intentionally to contrasting perspectives. This can be achieved at an individual level through activities such as reading about business leadership, attending a local conference on engineering education, or inviting theatre department faculty staff to offer a faculty development session. Similarly, we can practise what we preach about continuous lifelong learning by pursuing explicit personal goals for learning something outside our own comfort zones (such as investigating the principles of 'lean' management, 
learning about qualitative methods of research, or exploring theories of transformative learning). Horizons can be broadened at a collective level by inviting guest speakers or authors from other fields to provide an overview of recent developments in their own domains.

\section{Fostering collaboration}

Many projects, publications and presentations reflect the homogeneous perspective of a single institution and a single discipline. Fostering collaborations among colleagues who come from different places, both geographically and intellectually, can produce a richer understanding and a broader application. ${ }^{15}$ It is especially important to encourage collaborations across national boundaries and even more so across east-west and north-south global divisions. Medical education remains tightly tied to Europe and North America (English is still its lingua franca), but there are promising signs of an expanding range of national and cultural perspectives. This collaboration requires respect and intellectual humility, but will greatly benefit medical education.

\section{Instigating academic 'cultural' exchanges}

Like high school or university students who go to study in a different culture and then return to share their experiences and perspectives with their peers, medical education benefits from having members of our own community do the same. We can go out to other 'countries', such as those of business management, engineering, the military or the humanities, to learn a different way of thinking and can then bring back these insights to share with our own community. As examples of these exchanges, many faculty development programmes include models and practices of leadership derived from the business community. Many health systems are adopting quality improvement methods imported from the fields of industrial and operations engineering. Psychology and the humanities are informing efforts to promote reflection in doctors as they direct their own learning. Particularly helpful are translational summaries of foreign fields (e.g. chaos and complexity theory ${ }^{16}$ ) written for medical educators and available in our own literature.

\section{CONCLUSIONS}

In summary, the two values represented in this part of the Hippocratic Oath, intellectual humility and respect for colleagues, are highly relevant to medical educators, as well as to physicians. Indeed, these values are central to most professions. It is the practice and the behavioural consequences of these values that will have real impact on our field and on the quality of our community and our contributions. We all share the responsibility to promote these values over competing values that undermine humility and respect.

Contributors: Larry Gruppen is the sole author and responsible for the opinions expressed herein.

Acknowledgements: The author wishes to acknowledge the invaluable feedback provided by his colleagues at the University of Michigan Medical School, J Thomas Fitzgerald, PhD, Caren Stalburg, MD, MA, and Sally S Santen, MD, $\mathrm{PhD}$, and two anonymous reviewers.

Funding: none.

Conflicts of interest: none.

Ethical approval: none.

\section{REFERENCES}

1 Eva KW. Trending in 2014: Hippocrates. Med Educ 2014;48:1-3.

2 McNaughton N, LeBlanc V. The central role of emotional competence in medical training. In: Hodges BD, Lingard L, eds. The Question of Competence: Reconsidering Medical Education in the Twenty-first Century. Ithaca, NY: Cornell University Press 2012; 70-96.

3 Eva KW, Regehr G, Gruppen LD. Blinded by 'insight': self-assessment and its role in performance improvement. In: Hodges BD, Lingard L, eds. The Question of Competence: Reconsidering Medical Education in the Twenty-first Century. Ithaca, NY: Cornell University Press 2012;131-54.

4 Sniezek JA, van Swol LM. Trust, confidence, and expertise in a judge-advisor system. Organ Behav Hum Decis Process 2001;84:288-307.

5 Law J, Lodge P. Science for Social Scientists. London: MacMillan 1984.

6 Bruner JS. On Going Beyond the Information Given. Cambridge, MA: Harvard University 1957.

7 Gruppen LD. Is medical education research 'hard' or 'soft' research? Adv Health Sci Educ 2008;13:1-2.

8 Schuwirth L, Colliver J, Gruppen L et al. Research in assessment: consensus statement and recommendations from the Ottawa 2010 Conference. Med Teach 2011;33:224-33.

9 Ringsted C, Hodges B, Scherpbier A. 'The Research Compass': An Introduction to Research in Medical Education. AMEE Guide No. zr56. Dundee: Association for Medical Education in Europe 2011. 
10 Albert M. Understanding the debate on medical education research: a sociological perspective. Acad Med 2004;79 (10):948-54.

11 Albert M, Hodges B, Regehr G. Research in medical education: balancing service and science. Adv Health Sci Educ 2007;12:103-15.

12 Kaplan S. Beyond rationality: clarity-based decision making. In: Garling T, Evans GW, eds. Environment, Cognition, and Action. New York, NY: Oxford University Press 1991;171-90.

13 Bruner JS. On perceptual readiness. Psychol Rev 1957;64:123-52.
14 Croskerry P. The importance of cognitive errors in diagnosis and strategies to minimise them. Acad Med 2003;78:775-80.

15 O'Sullivan PS, Stoddard HA, Kalishman S.

Collaborative research in medical education: a discussion of theory and practice. Med Educ 2010;44: 1175-84.

16 Norman G. Chaos, complexity and complicatedness: lessons from rocket science. Med Educ 2011;45:549-59.

Received 15 February 2013; editorial comments to author 18 March 2013, accepted for publication 9 May 2013 